\title{
La comanda como instrumento crediticio en el Aragón moderno: Las compras de trigo adelantado por el pósito de Daroca (siglos XVI-XVII)
}

\author{
José Antonio Mateos Royo*
}

\section{LA CAMARA DEL TRIGO DE DAROCA DURANTE LOS SIGLOS XVI Y XVII: CARACTERISTICAS Y EVOLUCIÓN}

A partir de principios del siglo XVI, el municipio aragonés de Daroca, favorecido por un largo periodo de crecimiento económico y demográfico, inicia un proceso de expansión de los servicios ofrecidos a sus vecinos. El buen estado de las arcas del Concejo y el recurso al crédito configurarán, por lo tanto, la centuria del Quinientos como una etapa de desarrollo de las iniciativas municipales y del ámbito de lo público en general.

En una faceta tan importante para las ciudades del Antiguo Régimen como es la de la procura de un buen abasto a su población, la actividad municipal se traduce en la creación de dos Cámaras, una para el Trigo y otra para el Aceite, destinadas a adquirir estos productos y poder frenar a tiempo las eventuales carestías ocasionadas por las malas cosechas de uno u otro. Dotadas de una cierta autonomía a través de la propiedad de una serie de fondos en dinero y especie, por separado del resto de la Hacienda municipal, asi como de administradores propios, su gestión no dejaba de hallarse en definitiva supeditada al control del Concejo, quien no sólo nombraba y exigia responsabilidades cada año a sus administradores, sino que podia tomar decisiones por su cuenta que afectasen a su funcionamiento.

De estos dos organismos, sin duda alguna el más importante es la Cámara del Trigo, conformada como un verdadero Pósito a partir de una antigua alhóndiga en las primeras décadas del Quinientos '. Su creación

Universidad de Zaragoza.

Véase al respecto mi artículo "El Almudi de Daroca en el siglo xv: en torno a los origenes de un Pósito de Trigo", Aragón en la Edad Media. Zaragoza X-XI,1993, págs. 603-612. 
más temprana, los mayores volúmenes de producto almacenado y las enormes sumas de dinero que se llegaron a destinar a la Cámara del Trigo la configurarán como una pieza clave del mecanismo de gestión de bienes de propios y de la política de abastos municipal.

Situada en una comarca cerealista por excelencia, la política de compra-venta durante el XVI se basará en la adquisición de grandes cantidades de grano tras la llegada de la cosecha a precios bajos, y su almacenamiento en los silos del Pósito, hasta la llegada de los meses de soldadura, en que el agotamiento de las reservas de cereal del año anterior imponía a las familias mayores necesidades de este producto de consumo básico y, caso de no hallarse, disparaba sus precios. La actuación del Pósito, al ofrecer grandes cantidades de grano a un precio muy próximo al que corría en el mercado, detenía las tendencias a la especulación y el acaparamiento, y favorecía que el trigo de propiedad particular se pusiese a la venta en la plaza pública.

El clima frio y seco del que goza Daroca durante buena parte del año permitía que se fuesen almacenando cada vez mayores cantidades sin grandes riesgos de deterioro. La expansión demográfica del Quinientos, al generar una demanda constante de grano, permitía obviar el peligro de acumulación que suponía tal aumento de los stocks. Como mínimo desde mediados de siglo, el Pósito ya distribuía trigo no sólo en los meses anteriores a la siega sino todo a lo largo del año. En ocasiones, para dar salida al grano que llevaba más tiempo en la Cámara - el denominado "trigo viejo "- se recurría al procedimiento de ofrecer grano a la población a un precio un poco inferior al que era adquirido por el Pósito, lo que motivaba su absorción inmediata por los vecinos de la ciudad.

Por supuesto, la eficacia del sistema dependía de la relativa escasez de los años de carestía, que se veía suplida por lo acumulado en los años de buenas cosechas. Este equilibrio se romperá de forma dramática a fines del siglo xvi. En este momento, bien debido a la adversidad del clima o, como sucede en otras zonas, a rendimientos decrecientes por agotamiento del terreno cultivado, se suceden una serie de malas cosechas que desajustan el mercado de grano. No sólo se producen importantes aumentos en su precio, sino también violentas oscilaciones en su valor que quiebran el mecanismo clásico de compra-venta de trigo llevado a cabo por la Cámara, de especial delicadeza dadas las importantes cantidades de trigo almacenadas.

El Pósito debe hacer frente a los elevados costes que en estos momentos supone el adquirir gran cantidad de trigo, cuando los mercados se cierran y aumentan las practicas de reventa y especulación. Las bruscas oscilaciones de precios imponían en ocasiones, para evitar que se es- 
tropease el grano, su venta a un valor muy inferior al de su compra, lo que provocaba cuantiosas pérdidas al Pósito. El efecto combinado de estos dos factores llevó al Concejo a determinar, ya en los últimos años del siglo XVI, que era necesario restringir la ambiciosa política de compraventa desarrollada hasta ese momento por la Cámara.

El método elegido fue disminuir tanto las compras como las ventas. El grano era ofrecido a la población a un precio cada vez más alto respecto al de compra, lo que tendía a disminuir la demanda y a concentrarla en los meses de soldadura, durante los que el Concejo, si lo estimaba oportuno, podia permitirse venderlo a precios más razonables o incluso repartirlo al fiado. Con todo, en el cúmulo total de ventas del Pósito el grano ofertado al público por menudo irá cobrando un papel cada vez menos importante frente al suministro de trigo a las panaderias, el cual, pese a suponer cantidades cada vez más modestas, reportaba mayores beneficios a la Cámara.

Este proceso de reducción de ventas se completará, a mediados del siglo XVII, con la creación de un almacén de trigo desgajado del Pósito, al que se denominará Almudí, consagrado al monopolio de las transacciones de grano entre particulares en el interior de la ciudad. En principio administrado, el Concejo no tardará en arrendar los corretajes cobrados por moderar estos intercambios. Como medio para regular la provisión de grano en su Pósito, el municipio se reservaba ciertas prerrogativas de compra y venta en el Almudí. También disponía de diversas medidas de control sobre éste para evitar que el precio del trigo alcanzase niveles excesivos.

La disminución de las ventas creaba al Pósito el inconveniente adicional de la renovación de los stocks de grano. Para solucionarlo, la Cámara promoverá repartos obligatorios de trigo entre los vecinos de la ciudad durante los meses de soldadura, es decir, en las fechas en que más se pudiera necesitar. La suma total solía alcanzar los cuatrocientos o quinientos cahices, distribuidos en cantidades de medio, uno o dos cahíces, según la menor o mayor disponibilidad económica de cada cual, y, con ella, de la capacidad de devolverlo una vez llegada la cosecha. Junto con la cantidad de trigo prestada, se les cobraba, asimismo, cuatro o seis sueldos por cahiz para cubrir los gastos de la operación.

Al asumir estos "repartimientos" un carácter cada vez más forzoso, no tardan en configurarse como una pecha de la que los estamentos privilegiados - clero, hidalgos - se ven exentos. La oligarquía concejil, sin embargo, se suma a ellos para dar ejemplo. Como ocurría desde hacia ya mucho tiempo con las sisas -impuestos indirectos sobre el consumoestablecidas por el Concejo, su participación se vuelve condición necesaria para poder desempeñar cualquier cargo municipal. 
Pese a todo, esta práctica de repartir trigo a los vecinos de la ciudad año tras año no dejaba de suscitar la oposición de éstos, por cuanto con frecuencia era trigo malo, estropeado, el que se les entregaba y en años en que podian no experimentar ninguna necesidad del mismo. El Concejo debía recurrir cada vez con más frecuencia a la compulsión para forzar a los darocenses a tomar el grano y tras la siega, para devolverlo tras la cosecha. Si las Actas municipales refieren la continua resistencia de los vecinos, las rendiciones de cuentas del Pósito demuestran la no menor tenacidad de los cobradores del Concejo, así como su efectividad a la hora de cobrar las sumas de dinero y el trigo adeudado a la Cámara.

De esta manera se va produciendo un relevo. El anterior sistema de compra-venta va siendo sustituido como mecanismo de suministro a la población por los repartos de grano ${ }^{2}$, que cobran carta plena de naturaleza a mediados del siglo xvill para convertirse por su constancia y reiteración a lo largo de la segunda mitad de la centuria, junto con el cobro de las deudas, en la actividad más importante de la Cámara. Las compras de trigo, como se aprecia en el cuadro 1, se reducirán en su cuantía global y se ceñirán a la muy rentable adquisición de trigo para las panaderías, en especial del grano destinado a la elaboración de pan franco. Sólo a fines del Seiscientos la recuperación económica y demográfica propiciará un aumento de la demanda de trigo que permitirá el abandono de los repartos y su sustitución por la venta de trigo común al fiado como medio de suministro a la población.

\section{LAS COMPRAS DE TRIGO ADELANTADO: CARÁCTER Y CONTEXTO}

Las compras de trigo adelantado pueden definirse como aquellas adquisiciones de trigo que se realizaban con anterioridad a haberse recogido la cosecha por medio de apalabrar con el vendedor la entrega de una determinada cantidad en trigo tras la siega. El comprador, a cambio de esta garantia, testificada muy a menudo ante notario, daba al dueño del grano una suma de dinero que se solía completar cuando se entregaba el cereal, al fijarse su precio final.

Véanse otros ejemplos de estos repartos de trigo en BERNABE G॥, D: Hacienda y mercado urbano en la Orihuela foral moderna. Alicante, Instituto Juan Gil Albert, Diputacion de Alicante, 1989. págs. 260-269. Gutierrez Al onso, G. Estudio sobre la decadencia de Castilla. La ciudad de Valladolid en el siglo xvit. Valladolid. Universidad, 1989. págs. 245-246 
Se trataba, por lo tanto, de un procedimiento crediticio al que el campesino solía recurrir durante los meses de soldadura, cuando las disponibilidades de excedentes se hallaban agotadas y se necesitaba dinero hasta la llegada de la cosecha ${ }^{3}$. El propietario del trigo sacrificaba su disponibilidad de una parte del excedente y se comprometía a entregarlo a un particular a un precio determinado una vez recogido el grano; pero que por lo general solía ser bajo, dadas las circunstancias de la adquisición.

Los frecuentes abusos cometidos por los prestamistas en el precio de venta motivaron la necesidad de una legislación al respecto. Tanto en Aragón como en Castilla, en especial en las zonas de interior, más propensas a un rígido control del comercio de trigo, se trató de imponer unos límites que fijasen unos mínimos al precio de venta ${ }^{4}$. Para Castilla, las Cortes de 1528 ya lo establecían en aquél al que circulase el grano en el mercado en los quince días anteriores o posteriores a Nuestra Señora de Septiembre. En el caso concreto del reino aragonés, el procedimiento, muy similar, fue fijado en Cortes el año 1461, bajo el reinado de Juan II:

«E todo lo sobredito queremos haver lugar contra aquellos que en virtud de contratos debitorios o de comanda feytos entro aquí exigirán y pagarán usura, o scientement exigirán alguna cosa, que ultra la principal suerte sea obligada en frau de usura. Encara contra cualesquiere christianos, iodios o moros, qui de aqui adelant comprarán o comprar farán a dineros anticipados. Queremos empero que las ditas cosas se puedan comprar aún a dineros anticipados, según que a común precio valdrán. Es a saber, los panes por todo el mes de agosto, entro a Santa María de Setiembre $(\ldots)^{5} \%$

Pese a este tipo de regulaciones, la necesidad en que se encontraba el campesino a la hora de solicitar el préstamo y el hecho probable de que esta situación volviera a repetirse en años venideros permitía al acreedor establecer acuerdos de carácter usurario que perjudicaban de forma notable al campesino. Como consecuencia, éste siempre procuraba evitar tales

Este hecho fundamental to diferenciaria de la mohatra que, según Nöel Salomon era más bien utitizada por los campesinos para adquirir productos - $-\in$ especial telas - a comerciantes quien "se apoderaba de la cosecha en el periodo de precios bajos, la revendia en el periodo de penuria a precios altos". Véase Sal OMON. N., La vida rural castellana en tiempos de Felipe II. Barcelona, Planeta, 1973, págs. 255-257. El carácter de necesidad parece estar mucho mas presente en las comandas contratadas con la Cámara del Trigo de Daroca.

Véase ANES, G., Las crisis agrarias en la España Moderna. Madrid, Taurus, 1970, págs. 74. 75, y ur CAsiro, C., El pan de Madrid. El abasto de las ciudades españolas del Antiguo Régimen. Madrid, Alianza Editorial, 1987, pág. 87

Véase Savali, P. y PEnen. S., Fueros. Observancias y Actos de Corte del reino de Aragón. Zaragoza, Imprenta de Castro y Bosque, 1866, parte I. pág. 207 
acuerdos, que, como se verá, sólo adquirian una entidad importante ante la incidencia de las malas cosechas que colocaban al año siguiente al campesino en un estado de desprotección evidente.

Una vez sentados estos precedentes, sería oportuno determinar qué actitud guarda la Cámara del Trigo de Daroca respecto a las compras de trigo adelantado. En este aspecto, las rendiciones de cuentas del Pósito conservadas en las Actas municipales no resultan de utilidad, por cuanto, si bien informan de la evolución del trigo almacenado y el gastado por el Pósito, no ilustran sobre su carácter a la hora de ser adquirido.

Por este motivo, para una primera orientación, se ha tenido que recurrir a las cuentas de la Cámara ${ }^{6}$. Éstas sí proporcionan el tipo de información deseado, pero encierran el grave inconveniente de su escasez para el período que abarca todo el siglo XVI y la primera mitad del xVII, representado sólo por la contabilidad de los años 1527, 1548, 1560, 1564, 1565, 1580, $1605-1608,1622,1644,1645,1647$ y 1650.

Pese a estas deficiencias, se puede constatar que, si bien la presencia de las compras de trigo adelantado se registra ya desde mediados del siglo XVI, no es sino a partir de 1580 cuando empiezan a crecer en importancia, en una dinámica que se ve acrecentada en los restantes años del siglo XVII conforme se reduce el monto de las adquisiciones totales. Desde mediados del XVII, por el contrario, con la excepción de algún año como 1661 y para un período especialmente bien documentado, se aprecia que las compras de trigo adelantado han desaparecido en la práctica.

Las razones de esta localización están provocadas por las relaciones entre la política de la Cámara y los ciclos agrarios. Durante buena parte del siglo XVI, a pesar de que se cuenta con alguna mención aislada de que "muchos demandaban dineros avançados por trigo " ", la compra de trigo adelantado no parece revestir mucha importancia para el Pósito. En un período en el que predominan las buenas cosechas, resultaba más rentable para la Cámara proceder a la compra al contado de grandes cantidades de grano tras la cosecha, en los meses de septiembre a noviembre. Las contadas menciones de que se dispone informan de que cada

Véase Archivo Municipal de Daroca (en adelante AMD), Contabilidad de la Cámara del Trigo. (7.1.1), (7.1.2), (7.1.3), (7.2.1), (7.2.2), (7.3.1), (7.3.2), (7.3.3), (7.4.1), (7.4.2). (7.5.1), (7.5.2), $(7.5 .3),(7.5 .4),(7.6 .1),(7.6 .2),(7.6 .3),(7.6 .4),(7.7 .1),(7.7 .2),(7.7 .3),(7.8 .1),(7.8 .2),(7.8 .3)$, $(7.8 .4),(7.9 .1),(7.9 .2),(7.9 .3),(7.9 .4),(7.9 .5),(7.9 .6),(7.10 .1),(7.10 .2),(7.10 .3),(7.10 .4),(7.11 .1)$ $(7.11 .2),(7.11 .3),(7.11 .4),(7.11 .5),(7.11 .6),(7.11 .7),(7.12 .1),(7.12 .2),(7.12 .3),(7.12 .4),(7.12 .5)$. $(7.13 .1),(7.13 .2),(7.13 .3),(7.13 .4),(7.14 .1),(7.14 .2),(7.14 .3)$ y $(7.15 .1)$

Véase AMD, Actas Municipales (Act.Mun.), 1534, 29 de junio. 
vez con más frecuencia buena parte de estas cantidades eran suministradas por importantes comerciantes que accedian a ellas gracias al arrendamiento de derechos señoriales y diezmos eclesiásticos ${ }^{8}$.

Las violentas convulsiones de precios del siglo XVI cambiarán este panorama. Cada vez se presta mayor atención a las compras de trigo adelantado como método para proporcionarse una cierta cantidad de trigo a un precio razonable. Si bien parece que las importantes compras de grano de fines del Quinientos, debido a su carácter de urgencia, se realizan en su mayor parte al contado, la importancia de las compras de trigo al fiado no sólo no decrece en esta época, sino que, como se comprueba en el cuadro 1 , se mantendrá durante toda la primera mitad del siglo XVII como forma prioritaria de procura de trigo común por la Cámara.

La constancia del recurso a esta práctica se ve confirmada gracias a la información conjunta suministrada por los protocolos notariales, los libros de cuentas y las Actas municipales, al apreciarse que se compró trigo adelantado en al menos treinta años de los comprendidos entre inicios y mitad del XVII ${ }^{9}$. El interés cada vez mayor del Concejo por las compras de trigo adelantado se revela en su aparición cada vez más frecuente en las Actas municipales ${ }^{10}$ conforme se aproxima la mitad del siglo y decrece la disponibilidad financiera del municipio.

Las razones de este interés por comprar trigo al fiado se orientan a asegurarse un mínimo de reservas al precio más bajo posible. Con este sistema, la Cámara también moderaba la posibilidad de que se produjesen con motivo de sus adquisiciones súbitas alzas de precio en el mercado del grano, muy difíciles luego de controlar. Por lo tanto, aunque no deje de tenerse en cuenta a los labradores, el Pósito adelanta dinero más bien en función de sus necesidades de grano que de los problemas de éstos. Estas necesidades venian condicionadas tanto por las cantidades de trigo almacenadas en los graneros de la Cámara como por aquéllas que eran vendidas a la población.

\footnotetext{
Véase al respecto mi articulo: «El área de aprovisionamiento de la Cámara del Almudi de Daroca durante los siglos $\times v 1$ y $\times$ vil: la Comunidad de aldeas", Xiloca. Calamocha, 10, 1992, págs. 17-46.

Estos años son los de 1600, 1601, 1603, 1605, 1606, 1607, 1608, 1609, 1612, 1615, 1617. $1620,1621,1622,1623,1630,1631,1632,1634,1635,1638,1639,1641,1642,1644,1645$, $1646,1647,1648,1651$ y 1652.

Vease AMD, Act. Mun., 1617, 12 y 18 de mayo, 30 de junio, 4 de agosto, 1 de sept., 2 de oct., 1620, 8 de sept., 1623, 21 de abril. 10 y 13 de mayo, 1630, 19 de abril, 7 de junio, 1631, 25 de abril, 3 de mayo, 1632, 21 de mayo, 4 de sept., 1634, 26 de mayo, 1635, 30 de mayo, 3 de junio, 1638, 11 de junio, 1639, 27 de mayo, 1641, 5 de abril, 6 de sept., 1642, 16 de mayo, 5 de sept., 1644, 1 y 14 de abril, 7 de sept., 1645, 12 de mayo, 7 de julio, 1646, 7 de sept., 1648,24 de abril, 1651, 12 de mayo, 1652, 5 de abril.
} 


\section{CUADRO 1}

\begin{tabular}{|c|c|c|c|c|c|c|c|c|c|c|}
\hline & CUEN & TAS DE & LA CÁMA & $\mathrm{RA}: \mathrm{C}$ & OMPRAS & DE T & RIGO (15 & $18-17$ & 07) & \\
\hline Años & Compras por & adelantado & Compras atc & ontado & Compras pan & $\overline{\text { franco }}$ & Compras pa & a doce & TOTAL & \\
\hline $\begin{array}{l}1518 \\
1526\end{array}$ & & & & & & & & & $\begin{array}{l}635 c \\
408 c\end{array}$ & $\begin{array}{l}2 f \\
4 f\end{array}$ \\
\hline 1527 & & & $1079 c$ & $3 t$ & $51 \mathrm{c}$ & & $144 \mathrm{C}$ & & $1274 \mathrm{C}$ & $3 f$ \\
\hline 1548 & $85 c$ & $4 f$ & $815 c$ & $2 f$ & $369 c$ & & $115 c$ & & $1.385 c$ & $1 f$ \\
\hline 1560 & $175 \mathrm{c}$ & $2 f$ & $900 \mathrm{c}$ & $2 f$ & $248 c$ & $2 q$ & & & $1.324 c$ & $2 q$ \\
\hline 1564 & & & $1.040 \mathrm{c}$ & & $254 \mathrm{c}$ & $1 f$ & & & $1.294 \mathrm{C}$ & $1 f$ \\
\hline 1565 & $180 \mathrm{c}$ & $2 f$ & $1.327 \mathrm{C}$ & $3 f$ & $12 \mathrm{C}$ & & & & $1.519 \mathrm{c}$ & $3 f$ \\
\hline 1580 & $873 c$ & $2 f$ & $496 c$ & & & & & & $1.369 \mathrm{c}$ & $2 f$ \\
\hline 1605 & $311 \mathrm{c}$ & & & & $150 \mathrm{C}$ & & & & $461 c$ & \\
\hline 1606 & $414 c$ & $2 f$ & $1.186 \mathrm{c}$ & $2 f$ & & & & & $1.601 \mathrm{C}$ & \\
\hline 1607 & $402 \mathrm{C}$ & $3 f$ & $583 c$ & $3 f$ & & & & & $986 \mathrm{c}$ & $2 f$ \\
\hline 1608 & $1.220 \mathrm{C}$ & & $332 \mathrm{c}$ & $1 f$ & & & & & $1.552 \mathrm{c}$ & $1 f$ \\
\hline 1622 & $305 c$ & & & & & & & & $305 c$ & \\
\hline 1644 & $251 \mathrm{c}$ & $2 f$ & & & & & $384 \mathrm{c}$ & & $635 c$ & $2 f$ \\
\hline 1645 & $74 \mathrm{C}$ & $2 f$ & $3 c$ & $2 f$ & $110 \mathrm{C}$ & & $67 \mathrm{c}$ & & $255 \mathrm{c}$ & \\
\hline 1647 & $386 \mathrm{c}$ & & & & $115 \mathrm{C}$ & & $51 \mathrm{c}$ & $2 f$ & $552 c$ & 21 \\
\hline 1650 & & & & & $20 \mathrm{c}$ & & & & $20 c$ & \\
\hline 1653 & & & & & $204 c$ & $1 f$ & $83 c$ & $2 f$ & $287 c$ & $3 f$ \\
\hline 1654 & & & & & $30 c$ & & & & $30 c$ & \\
\hline 1655 & & & & & $168 \mathrm{c}$ & $2 f$ & $1 \mathrm{c}$ & & $169 c$ & $2 f$ \\
\hline 1656 & & & & & $51 \mathrm{C}$ & 21 & & & $51 \mathrm{c}$ & $2 f$ \\
\hline 1658 & & & & & $112 \mathrm{C}$ & $2 f$ & & & $112 \mathrm{c}$ & $2 f$ \\
\hline 1661 & $334 \mathrm{c}$ & $2 f$ & & & $43 c$ & $3 f$ & $450 \mathrm{C}$ & $2 f$ & $828 \mathrm{c}$ & $3 t$ \\
\hline 1662 & & & & & $110 \mathrm{C}$ & $3 f$ & $116 \mathrm{c}$ & $2 f$ & $227 \mathrm{c}$ & 11 \\
\hline 1664 & & & & & $292 c$ & $3 f$ & & & $292 \mathrm{c}$ & 31 \\
\hline 1665 & & & & & & & $1.341 \mathrm{C}$ & 19 & $1.341 \mathrm{c}$ & 10 \\
\hline 1669 & & & $827 \mathrm{c}$ & $1 f$ & & & & & $827 c$ & $1 f^{9}$ \\
\hline 1670 & & & & & $192 \mathrm{C}$ & $2 f$ & $99 c$ & & $291 c$ & $2 f$ \\
\hline 1672 & & & & & $105 \mathrm{C}$ & & & & $105 \mathrm{c}$ & \\
\hline 1673 & & & $123 c$ & $1 f$ & & & & & $123 c$ & $1 f$ \\
\hline 1675 & & & $45 c$ & $1 f$ & & & & & $45 c$ & $1 f$ \\
\hline 1678 & & & & & & & & & $34 \mathrm{C}$ & 21 \\
\hline 1680 & & & & & $148 \mathrm{C}$ & $2 f$ & $241 \mathrm{c}$ & & $389 \mathrm{c}$ & $2 f$ \\
\hline 1682 & & & & & $48 c$ & $3 f$ & $108 \mathrm{c}$ & $1 f$ & $157 \mathrm{C}$ & \\
\hline 1683 & & & & & $91 \mathrm{c}$ & if & $2 \mathrm{C}$ & $1 f$ & $93 \mathrm{c}$ & $2 f$ \\
\hline 1684 & & & & & & & & & $1.247 \mathrm{C}$ & $2 f$ \\
\hline 1685 & & & $6 \mathrm{c}$ & $3 f$ & & & & & $6 c$ & $3 f$ \\
\hline 1687 & & & & & $65 c$ & if & & & $65 c$ & if \\
\hline 1690 & & & & & $58 \mathrm{c}$ & $2 f$ & & & $58 \mathrm{c}$ & $2 f$ \\
\hline 1692 & & & $13 c$ & & & & & & $13 c$ & \\
\hline 1695 & & & $178 \mathrm{c}$ & & & & & & $178 \mathrm{c}$ & \\
\hline 1696 & & & $767 \mathrm{C}$ & 19 & & & & & $767 \mathrm{c}$ & $1 q$ \\
\hline 1698 & & & $254 \mathrm{c}$ & $1 f$ & & & & & $254 \mathrm{c}$ & if \\
\hline 1699 & & & $1.413 \mathrm{c}$ & & & & & & $1.413 \mathrm{C}$ & \\
\hline 1701 & & & & & & & & & $794 \mathrm{C}$ & $3 f$ \\
\hline 1702 & & & $1.028 \mathrm{c}$ & & & & & & $1.028 \mathrm{c}$ & \\
\hline 1705 & & & $372 \mathrm{c}$ & if & & & & & $372 \mathrm{C}$ & $1 f$ \\
\hline 1707 & & & $184 \mathrm{C}$ & $2 f$ & & & & & $184 \mathrm{C}$ & $2 f$ \\
\hline
\end{tabular}

Abreviaturas Evolucion de las medidas de capacidad para áridos en Daroca a lo largo del sigio $\times$ v

\begin{tabular}{|c|c|c|c|}
\hline$=$ cahiz & De inicios a mediados del $x \mathrm{v}$ & En la decada de los sesenta & A partir de 1578 en ade \\
\hline fanega & un cahiz $=5$ tanegas & un cahiz $=4$ fanegas & un cahiz $=4$ fanegas \\
\hline tia & una fanega $=2$ medias & una fanega $=2$ medias & una fanega $=2$ medias \\
\hline & una fanega $=4$ cuartales & una fanega $=3$ cuartates & una fanega \\
\hline
\end{tabular}

La última modificación de las medidas de capacidad para aridos se mantiene a lo largo de todo el siglo xvil. Según estimaciones propias. el cahiz de Daroca pasa de suponer unos 145.82 kilogramos y 186. 1 litros a los 140 kilogramos y 179.36 litros en que consistia el cahiz de Zaragoza. patrón oficial para todo el reino aragonés. Las unidades inferiores se distribuyen de forma distinta a las de la capital. pero guardan con respecto a éstas relaciones de equivalencia. El sistema de medidas, por tanto. ha tendido a homogeneizarse con el de Zaragoza con vistas a facilitar las transacciones comerciales. 
En este sentido, se comprueba que la correspondencia exacta que existía a lo largo del XVI entre el precio de venta de trigo en el Pósito durante los meses de septiembre y octubre con el de compra del trigo adelantado por la misma Cámara se va abandonando cada vez en mayor medida. Esta disociación es fruto del hecho de que el Pósito pretende mantener unos precios de venta altos tanto para retraer la demanda como para conseguir de paso ingresos adicionales. El precio de compra del trigo adelantado será, sin embargo, inferior al de venta por el Pósito para no hacer partícipes a los vendedores del trigo adelantado de ese mismo grado de beneficio.

Los problemas que planteaba la adquisición de trigo adelantado justifican la atención que le dedica el Concejo. En primer lugar, el proceso tan laborioso de su recogida, que en verdad sólo se completaba en marzo del año siguiente, cuando la rendición de cuentas por el administrador obligaba a solventar las deudas en trigo de una vez. En segundo término, la vigilancia para que el trigo se entregue en buen estado, sin que esté podrido ni mezclado con centeno, como se decide en septiembre de 1620:

"Que se procure y tenga mucho cuidado de que se resciva trigo puro y no centenoso, pues el precio es justo, y este año se coge buen pan y limpio" ${ }^{11}$.

A estas dificultades se unia el establecimiento de un precio inicial que le pareciese al labrador lo suficientemente atractivo para decidirse a vender su trigo por adelantado a la Cámara y no a los muchos compradores de grano que utilizaban el mismo procedimiento para adquirirlo. Este es el motivo, por ejemplo, que forzará al Concejo a subir en 1631 el precio del cahíz de trigo adelantado de 38 a 40 reales $^{12}$. La suma de dinero adelantada debía ser lo bastante moderada como para dejar un margen a la «refaction» que satisfaciese tanto a los intereses de los vendedores como a la administración de la Cámara. En ocasiones, la diversidad del grano entregado era tal que el municipio debe plantearse que "será bien señalar conforme los trigos se traxeren" ${ }^{13}$, es decir, en función de su diversa calidad.

Por añadidura, las cantidades de trigo vendidas por adelantado solian ser pequeñas. En muchas ocasiones, consistian en lo justo para conseguir el dinero con que parchear los meses de soldadura. Sólo el espectro del endeudamiento, motivado por años de auténtica carestia -1606, 1615,

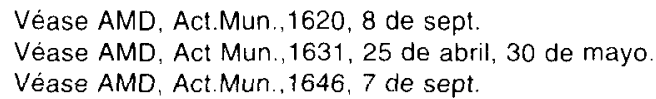


1617-, o de forma ocasional la perspectiva de una muy buena cosecha ${ }^{14}$ -1580, 1608-, que haría bajar los precios del grano y dificultaría la venta de los excedentes, podian decidir al campesino a entregar grandes cantidades de trigo a la Cámara.

\section{LA DINÁMICA DE CONTRATACIÓN DE TRIGO ADELANTADO: LAS COMANDAS}

\subsection{Las comandas: caracteristicas}

Para el estudio concreto de las formas de establecerse las compras de trigo adelantado se ha tenido que utilizar otra fuente distinta a las ya empleadas. Se trata de las comandas establecidas entre vendedores de trigo al fiado y los administradores del Pósito, las cuales menudean en los protocolos ${ }^{15}$ de los notarios que trabajan para el municipio durante el último tercio del siglo XVI y el primero del XVII. Esta documentación encierra el valor de que ilumina una vertiente de la actividad del Pósito no mencionada en las Actas municipales hasta el siglo XVII -y aun entonces sólo de forma muy sesgada - y sobre la que la contabilidad de la Cámara apenas aporta detalles más allá de los datos cuantitativos.

El carácter a menudo fragmentario y disperso de la documentación notarial impone ciertas reservas. No siempre se tiene la seguridad de que las comandas conservadas en el protocolo de un notario sean la totalidad de las contraídas con la Cámara durante ese año, ni siquiera del grado de ocultación al respecto. De algunos años -1588, 1589, 1617-, la misma desaparición de parte del protocolo confirma que parte de la información se ha perdido. El recurso a otro notario aparece, por ejemplo, constatado en 1605,1607 y 1608 . El ejemplo del año 1605, en que coinciden comanda tras comanda las halladas en el protocolo notarial con las partidas de compras de trigo adelantado registradas en el libro de cuentas de la Cámara correspondiente al mismo año, permite también comprobar que algunas comandas no aparecen registradas en la fuente recíproca. No obs-

\footnotetext{
14 Una caracteristica de estos años es que la llegada de la siega no interrumpe la compra de trigo adelantado, que se sigue efectuando con la remisión del valor final del trigo a los precios al mes de septiembre

15. Véase Archivo de Protocolos Notariales de Daroca (en adelante APND), Pablo Pastrana, 1581. Pedro Manente, 1583. Tomás Zorrilla, 1587, 1591, Miguel Domingo de Latorre, 1582, 1588, $1589,1593,1599,1600,1603$, Lupercio Gonzalo, 1601, Jerónimo Martínez, 1605, Miguel Casanova, 1617, 1620, Tomás Zorrilla de las Arenas, 1615, 1634, 1635.
} 
tante, por lo observado para este año en concreto, ambos casos son excepcionales y afectan a cantidades de poca importancia.

En consecuencia, como medida de precaución, las cifras que se utilizarán en el presente estudio reflejadas en el cuadro 2 deben tomarse siempre como minimas, susceptibles al alza. Al respecto, he considerado aceptable la hipótesis de que una anotación más o menos regular y constante dice mucho en favor de la fiabilidad, siempre relativa, del documento. Una vez hallado un número apreciable de comandas -que superen los 150 caníces, por ejemplo-, si guardan un ritmo de contratación constante, se puede hablar ya de una muestra lo suficientemente significativa para configurar una cierta tendencia para ese año. Dentro de la misma linea de cautela, nunca se afirmará que, por el hecho de no localizar comandas en un protocolo, no se hayan efectuado compras por adelantado dicho año.

El documento legal de la comanda, de amplia implantación ya en la Edad Media ${ }^{16}$, supone en sí el reconocimiento de que se adeuda una determinada cantidad en especie o en dinero a un particular o institución. Este hecho no siempre quiere significar que esa cantidad se haya recibido, como sucede con las compras de trigo adelantado. No se trata de ningún préstamo de grano realizado por el Pósito, sino que su auténtico significado es establecer un compromiso por parte de un individuo o varios de acudir a la Cámara, tras la siega, para aportar una cantidad concreta de trigo. A cambio de esta obligación contraída, se adelanta a esta persona o personas una determinada suma de dinero en el momento de contratar la comanda, suma a la que se añadirá una compensación una vez entregado el grano para que alcance los precios del grano que imperan en el mes de septiembre.

Caso de que el comprador no pudiese demostrar la solvencia suficiente como para avalar la entrega del grano o simplemente, que fuese forastero, era indispensable para vender su grano el hacerse acompañar ante la Cámara por un vecino de la ciudad que desempeñase el papel de fiador o fianza y garantizase con su hacienda el pago del trigo al que se obliga-

\footnotetext{
El uso de la comanda cuenta con una larga difusión ya en la época medieval en la Corona de Aragón. Véase, por ejemplo, Madurell, J.M. y Garcia Sanz, A., Comandas comerciales barcelonesas de la Baja Edad Media. Barcelona, Colegio Notarial, 1973 y LARA, P: "Fórmulas crediticias medievales en Aragón: Zaragoza, centro de orientación crediticia», Jerónimo Zurita, Zaragoza, 45-46, 1983, págs. 7-90. Véase también Clivan JarouE, M.I. "Notas sobre el desarrollo usurario de los valles de Matarraña, Guadalope y Mijares en el último tercio del siglo Xv". Teruel, Teruel, 57 58, 1977, págs. 109-128
} 
ba el contratante. Por supuesto, la labor de fianza comportaba cierta retribución por el servicio, razón que explica la insistencia con que algunas personas se prestaban para ejercer este papel. La condición social del fianza resultaba de suma importancia por cuanto condicionaba la cantidad de grano que el vendedor podía avalar ante el Pósito.

Una vez efectuado el acuerdo con la Cámara, el contratante con mucha frecuencia otorgaba acto seguido un compromiso de garantía a su fiador que podía adoptar diversas formas. El vendedor de trigo adelantado podía obligarse mediante un acto de indemnidad por el que se comprometía a restituir a su fianza todos los perjuicios que le pudiesen sobrevenir por haberse obligado con él. Otro procedimiento consistía en contraer otra comanda por la misma cantidad con su garante, seguida por lo general de una contracarta en la que éste reconocía su derecho exclusivo a valerse de la anterior comanda sólo en el caso de que la persona de la que respondía no pagase al cambrero el trigo debido y éste recurriese a él, fianza, para cobrarle la deuda ${ }^{17}$.

Como ya se ha puesto de manifiesto con anterioridad, este trigo se compraba a la población durante los meses de soldadura, cuando se agotaban las reservas de grano almacenadas en los graneros y el campesino necesitaba dinero ${ }^{18}$. Las compras se recrudecían conforme se acercaba la siega -que en 1601 parece hacerse desear hasta pasados mediados de agosto-, cuya consecución marcaba por lo general el fin de estas operaciones, al preferir el campesino de manera lógica negociar con su trigo que depender del precio fijado por la Cámara.

\footnotetext{
Véase, por ejemplo, la carta de indemnidad establecida el 25 de junio de 1601 por Juan Benedicto, vecino de Cosa, en favor de Juan Pascual, de Daroca, por la que aquél "se obliga a sacar indemne a Joan Pasqual por cualquier daño que le viniere de haberse obligado en la presente cantidad". También paradigmáticos resultan los términos de la contracarta establecida el 8 de mayo de 1601 por Miguel Gil, fianza de Joan Felipe, vecino de Romanos, en la que, tras recibir una comanda en su favor, "se compromete a no valerse de la comanda sino en caso de que pagase al dicho cambrero el dicho trigo". Éstos y otros ejemplos en APND, Pablo Pastrana, 1581, 2 de julio, Tomás Zorrilla, 1587, 2 de junio, Lupercio Gonzalo, 1596, 25 de junio y 1601, 8, 9 y 20 de mayo, 25 de junio, 5 y 15 de agosto. Tomás Zorrilla de las Arenas, 1615, 7 de abril, 10 de mayo.

18 Esta actitud, por lo demás, era desarrollada durante el último cuarto del siglo XVI por comerciantes de cierto peso como Juan Marcuello, Luis de Alberuela o Miguel Escolano. A partir del siglo XVII se observará en estos negocios la presencia de mercaderes franceses procedentes de la Ubernia y el Bearn: Bernad de Trosill, Pedro Belat, Pedro Forcada, Fortanet de la Abadia, Antón Fabré, Juan de Lamoros, Antón de Ribera y Juan de Sartessa. Destaca su actuación en momentos de mala coyuntura agricola - -1615, 1617-, cuando la mala cosecha del año anterior forzaba al campesino a contratar estos compromisos. Véase APND, Tomás Zorrilla, 1587, 1591, Miguel Domingo de la Torre, 1588, 1589, 1592, 1599, 1600, 1603, Lupercio Gonzalo, 1601, Jerónimo Martínez, 1605, Miguel Casanova, 1617, 1620 y Tomás Zorrilla de las Arenas, 1612, 1615, 1634, 1635.
} 


\section{CUADRO 2}

\begin{tabular}{|c|c|c|c|c|c|c|c|c|c|}
\hline \multirow{3}{*}{$\begin{array}{l}\text { AÑOS } \\
-1581\end{array}$} & \multicolumn{3}{|c|}{ DAROCA } & \multicolumn{3}{|c|}{ ALREDEDORES } & \multicolumn{3}{|c|}{ TOTAL } \\
\hline & \multirow{2}{*}{ de $\begin{array}{c}\begin{array}{c}\text { Numero } \\
\text { Comandas }\end{array} \\
16\end{array}$} & \multicolumn{2}{|c|}{$\begin{array}{l}\text { Cantidad } \\
\text { de Trigo }\end{array}$} & \multirow{2}{*}{$\frac{\begin{array}{c}\text { Número } \\
\text { de Comandas }\end{array}}{22}$} & \multicolumn{2}{|c|}{$\begin{array}{l}\text { Cantidad } \\
\text { de Trigo }\end{array}$} & \multirow{2}{*}{$\frac{\begin{array}{c}\text { Número } \\
\text { de Comandas }\end{array}}{38}$} & \multicolumn{2}{|c|}{$\begin{array}{l}\text { Cantidad } \\
\text { de Trigo }\end{array}$} \\
\hline & & $73 c$ & $3 f$ & & $90 \mathrm{c}$ & & & $163 c$ & $3 f$ \\
\hline 1582 & 21 & $166 c$ & & 11 & $87 \mathrm{c}$ & & 32 & $253 c$ & \\
\hline 1583 & 23 & $80 \mathrm{c}$ & $2 f$ & 15 & $70 \mathrm{c}$ & & 38 & $150 \mathrm{c}$ & $2 \dagger$ \\
\hline 1587 & 19 & $102 \mathrm{c}$ & & 25 & $173 c$ & & 44 & $275 c$ & \\
\hline 1588 & 52 & $149 \mathrm{c}$ & $2 f$ & 26 & $178 \mathrm{c}$ & $2 f$ & 78 & $328 \mathrm{c}$ & \\
\hline 1589 & 12 & $36 c$ & & 6 & $72 c$ & & 18 & $118 \mathrm{c}$ & \\
\hline 1591 & 171 & $276 \mathrm{c}$ & & 33 & $154 \mathrm{c}$ & $3 f$ & 201 & $430 \mathrm{c}$ & $3 f$ \\
\hline 1593 & 38 & $117 c$ & $3 f$ & 5 & $28 \mathrm{c}$ & & 43 & $145 \mathrm{c}$ & $3 f$ \\
\hline 1599 & 21 & $81 c$ & $2 f$ & 11 & $87 \mathrm{C}$ & 21 & 42 & $169 \mathrm{c}$ & \\
\hline 1600 & 17 & $77 \mathrm{c}$ & & 9 & $45 c$ & & 26 & $122 c$ & \\
\hline 1601 & 54 & $147 \mathrm{C}$ & $2 f$ & 49 & $257 \mathrm{c}$ & & 103 & $404 c$ & $2 f$ \\
\hline 1603 & 21 & $53 \mathrm{c}$ & $2 f$ & 22 & $118 \mathrm{c}$ & & 43 & $171 c$ & $2 f$ \\
\hline 1605 & 124 & $296 \mathrm{C}$ & $2 f$ & 23 & $81 \mathrm{c}$ & $2 f$ & 147 & $372 \mathrm{c}$ & \\
\hline 1612 & 4 & $18 \mathrm{c}$ & & 13 & $73 c$ & & 17 & 910 & \\
\hline 1615 & 187 & $460 \mathrm{c}$ & $1 f$ & 97 & $458 \mathrm{c}$ & & 284 & $918 \mathrm{c}$ & $1 f$ \\
\hline 1617 & 32 & $133 \mathrm{c}$ & $2 i$ & 73 & $447 \mathrm{c}$ & $2 f$ & 105 & $581 \mathrm{C}$ & \\
\hline 1620 & 64 & $229 c$ & & 33 & $172 \mathrm{c}$ & $2 f$ & 107 & $401 c$ & $2 f$ \\
\hline 1634 & 25 & $111 \mathrm{c}$ & $2 f$ & 2 & $8 c$ & & 27 & $119 c$ & $2 t$ \\
\hline 1635 & 64 & $288 \mathrm{C}$ & 24 & 20 & $109 c$ & $2 f$ & 84 & $398 c$ & \\
\hline
\end{tabular}

$c=$ cahices: $\{=$ tanegas

Por este motivo, no resulta de extrañar que las cifras expuestas en el cuadro 2 confirmen este escaso amor por las ventas por adelantado, impuestas en definitiva por la escasez durante los meses de soldadura. El hecho de que la Cámara empiece a comprar grano en fechas tempranas y cantidades notables suele ser indicio seguro de que la cosecha del año anterior resultó escasa, por lo que las disponibilidades de dinero por amplios sectores del mundo rural se hallan agotadas y deben vender trigo por adelantado. Si la necesidad de crédito se halla siempre latente en el mundo rural ${ }^{19}$, los apuros vividos ante las malas cosechas le conceden un decidido carácter de urgencia.

Veanse al respecto las apreciaciones sobre la utilidad y función dinamizadora del crédito en el mundo rural de LOPEZ SALAZAR, J., Estructuras agrarias y sociedad rural en la Mancha (siglos Xvixvm). Ciudad Real. Diputación Provincial, 1986, págs. 609-664 y VASSBERG, D.E., Tierra y sociedad en Castilla. Barcelona, Crítica, 1986, pàgs. 264-265 
De este modo, los 918 cahices que se conservan registrados para 1615 , año de gran escasez, empiezan a ser contratados ya a principios de marzo. En 1591 el Concejo combina la venta de trigo al fiado para alimentar a la población a principios de abril con la compra de grano adelantado a partir de fines del mismo mes. Una constante, la importancia de las compras en abril y mayo, caracteriza por igual a los años de 1588, 1605, 1620 y 1635, en los cuales las cifras de grano rondan, si no sobrepasan, los cuatrocientos cahices.

Para otros años - 1583, 1587, 1599- en que la adquisición de grano al fiado es menor, ésta suele comenzarse a principios de mayo y durar hasta, por lo general, fines de julio. En todos ellos, el incremento de las compras por adelantado de cereal a partir de principios o mediados de junio se percibe de forma clara, en sintonía con la necesidad de dinero por los vecinos de la ciudad. A veces, sin embargo, la distribución de las contrataciones de grano es más regular y abarca un período más extenso, como 1581, en que se inician a principios de abril; o en 1593, desde fines de marzo. Este último año, por cierto, resulta un buen ejemplo de cómo la llegada de la cosecha a fines de junio parece propiciar que esta dinámica de venta no se incrementase.

Siempre en función de las necesidades del campesino, el periodo de contratación puede reducirse todavía más: entre principios de junio y mediados de julio en 1600, de primeros de mayo a mediados de junio en 1634 , o de fines de junio a los de julio en 1612. Esta reducción del período de contratación conlleva, de forma lógica, la de la cantidad de trigo apalabrado. Sin embargo, en ocasiones un período corto de tiempo no es obstáculo para que exista una verdadera concentración de comandas: en 1582, sólo entre principios de junio y mediados de julio se concierta la compra al fiado de 253 cahices.

Respecto a la procedencia del trigo adelantado, la contemplación del cuadro 2 demuestra que la vecindad de Daroca y los habitantes de la comarca se alternan en la primacía. En determinados años -1588, 1591, $1601,1605,1615-$, algunos de auténtica escasez, las compras se dirigen en primer lugar a los vecinos de Daroca y sólo pasado un tiempo figuran forasteros como contratantes de grano. La razón puede deberse al intento de la Cámara de favorecer en lo posible a los vecinos de la ciudad, a la vez que se aseguraba, gracias a su mayor proximidad, mayores facilidades a la hora de la entrega del grano.

\subsection{La extracción social de los contratantes.}

Al margen de las anteriores precisiones de índole numérica, el estudio de las comandas ofrece el gran aliciente de proporcionar mayor informa- 
ción que las cuentas de la Cámara sobre los contratantes del trigo adelantado, es decir, las personas - por lo común, dos o tres-, que reconocían adeudar a la Cámara una determinada cantidad de trigo que solía oscilar entre uno y cuatro cahíces. No obstante, antes de abordar su estudio, debo realizar la advertencia preliminar de que la contratación de comandas expone la existencia de una multitud de lazos de parentesco, religiosos, profesionales, de negocios,... Este amplio mundo de relaciones desata un gran número de acuerdos personales que siguen resultando desconocidos y dificultan cualquier aproximación a la figura de los contrayentes de estos compromisos.

Por estas razones he considerado más oportuno en el cuadro 3 , en vez de representar todas las posibles combinaciones de estratos sociales que intervienen en la compra de trigo adelantado, elaborar un cuadro más sencillo que pusiera de manifiesto la constatación más importante: la presencia mayoritaria de labradores en estos acuerdos. Una vez establecido este punto primordial, se establecerán las matizaciones oportunas respecto a las motivaciones que empujan hacia la venta de trigo adelantado a otros sectores sociales.

En primer lugar se ha procedido a una selección de los años en que la procedencia social de los contratantes era más clara, no sin procurar cubrir de manera más o menos regular el período estudiado. La cantidad total de trigo presente en las comandas ha sido distribuida en tres grupos: el del grano contratado parcial o totalmente por labradores, el del apalabrado en exclusiva por otros sectores sociales y aquél en el que la procedencia social de los contratantes no se ha podido determinar. De las cantidades resultantes se ha extraído el porcentaje respecto del total para facilitar las comparaciones.

\section{CUADRO 3}

\begin{tabular}{cccc}
\hline \multicolumn{4}{c}{ CONTRATANTES DE TRIGO ADELANTADO: EXTRACCIÓN SOCIAL } \\
\hline AÑOS & LABRADORES & OTROS SECTORES & INDETERMINADOS \\
\hline 1588 & $58,90 \%$ & $7,77 \%$ & $33,23 \%$ \\
1593 & $54,85 \%$ & $31,74 \%$ & $13,40 \%$ \\
1601 & $50,86 \%$ & $24,57 \%$ & $24,57 \%$ \\
1605 & $60,78 \%$ & $34,63 \%$ & $4,58 \%$ \\
1615 & $52,73 \%$ & $25,79 \%$ & $21,48 \%$ \\
1620 & $66,78 \%$ & $30,49 \%$ & $2,73 \%$ \\
1635 & $49,75 \%$ & $41,96 \%$ & $8,23 \%$ \\
\hline
\end{tabular}


A simple vista se puede apreciar la superioridad del estamento de los labradores en las comandas establecidas con la Cámara. Esta preeminencia resulta lógica por cuanto se trata del estrato social en que coincide en mayor medida la necesidad durante los meses de soldadura con la posibilidad de legitimar la entrega de trigo tras la siega.

En cuanto al resto de los sectores sociales, su presencia obedece a diversas explicaciones. Por un lado, se conservan bastantes menciones de menestrales, en su mayoría vecinos de la ciudad que, en idéntica situación de necesidad que los labradores, pueden avalar cierta cantidad de grano. No es extraño en una ciudad como Daroca, muy imbricada en su contexto rural y en que los gremios no tenían el peso y la conformación interna tan acabada de una gran ciudad. Muchos vecinos compaginarían el desempeño de su oficio de menestral con la posesión de parcelas y el trabajo en el campo.

Por otro lado, también se halla representado el estamento de ciudadanos, más próximo a la oligarquía municipal: notarios, médicos, mercaderes... Su participación gana en constancia conforme las cantidades avaladas en las comandas son de mayor cuantia. En muchas ocasiones, representan de forma clara el papel de fianzas de menestrales o labradores, bien vecinos de Daroca o forasteros. En otras, al constatarse su sola mención en la comanda, parecen actuar en representación de otras personas, por su mayor capacidad de aval.

La presencia del clero también parece ir orientada en este sentido. Tienen menos importancia como contratantes efectivos de trigo adelantado que como fiadores de menestrales o labradores, en general por cantidades situadas entre los cinco y los diez cahices. Muchas de estas comandas dejan traslucir también que su papel de fianzas viene determinado a menudo más por su condición de familiares de los vendedores que por mero interés. Como sucede con los ciudadanos, también pueden actuar como intermediarios. Es el caso, por ejemplo, de los vicarios de las aldeas de los alrededores.

\section{CONCLUSIONES}

Como conclusiones, se puede reseñar que, pese a la enorme dificultad de análisis que suponen las comandas, ha quedado clara la primacia de la participación por parte de los estratos de labradores, con especial preeminencia del elemento campesino entre los contratantes avecindados en el territorio en torno a la ciudad. El papel predominante de las pequeñas can- 
tidades en esta serie de ventas enlaza con el proceso descrito de la compra por adelantado durante los meses de soldadura. Se vende sólo lo necesario para esperar a la llegada de la cosecha.

Conforme incida con mayor fuerza la crisis finisecular, las compras de trigo adelantado se incrementarán al compás de los años de malas cosechas y de los apuros que esperan al campesino hasta poder recoger la cosecha al año siguiente. La Cámara del Trigo, agobiada por cada vez mayores dificultades financieras, no vacilará en sacar provecho de las circunstancias para adquirir grano a unos precios fijados en última instancia por ella misma. Este último factor propiciará que la tasación establecida por los administradores del Pósito sobre el trigo adquirido por adelantado se vuelva cada vez menos favorable para el vendedor y más rentable para la Cámara.

Con el conocimiento de estas características favorables - período de crecientes dificultades económicas para el campesino, establecimiento del precio final por la Cámara - resulta perfectamente comprensible que las adquisiciones por adelantado desempeñen un papel destacado en el cada vez más modesto mecanismo de aprovisionamiento mantenido por el Pósito durante la primera mitad del Seiscientos. La información proporcionada por las comandas revela no sólo su importancia tras años de malas cosechas - 1615,1617-, sino también su constancia y asiduidad, pese a tratarse de cantidades modestas, en bastantes otros.

El protagonismo de las compras por adelantado no representa sino el intento realizado por el Pósito de preservar, al menos en parte, el papel desempeñado durante el siglo XVI como entidad abastecedora de trigo a la ciudad. En sintonía con otros comportamientos adoptados por el municipio en su política fiscal -repartimentos, sisas-, la consecución de este objetivo se obtendrá de forma fundamental a costa de los vecinos de la ciudad, en especial de los sectores más humildes, representados por la inmensa mayoria de los vendedores de trigo al fiado.

Como consecuencia, parece claro que en las orientaciones de la actividad creditica de la Cámara del Trigo priman la protección al consumidor sobre la del productor, descompensación percibida en toda la politica municipal y que se constituye en característica propia de los núcleos urbanos durante el Antiguo Régimen ${ }^{20}$. Si la primera se demuestra bien

Véase AyMARD. M., "Autoconsommation et marchés: Chayanov, Labrousse ou Le Roy Ladurie?", Annales. Economies. Societes. Civilisations, Paris 1983, págs. 1392-1410 y HFRLIHY, D. "The Distribution of Wealth in a Renaissance Community: Florence, 1427", en: ABRAMS, P.H.y Wrigley, E.A. (eds.). Towns in Societies. Cambridge, Universidad, 1978, págs. 145-153 
visible en todo el proceso del arriendo de bienes de propios por el Concejo, la segunda sólo se ve reflejada en la defensa por la ciudad del sistema de regadios o en el trato preferencial dado a los labradores de Daroca en el mercado para vender productos como trigo y vino en años de sobreproducción.

En definitiva, el mantenimiento de esta mentalidad impide que la compra de trigo adelantado por el Pósito desempeñe un papel importante a la hora de evitar el proceso de endeudamiento del labrador, señalado para otras zonas por diversos autores ${ }^{21}$, que la existencia de las mismas comandas demuestra. Más que constituir una alternativa a las compras de trigo adelantado realizadas por grandes mercaderes, las adquisiciones de la Cámara se suman a una tendencia ya existente que conducirá, al ser desposeído de sus tierras el pequeño propietario insolvente, a importantes cambios en la propiedad del suelo y, por ende, en las relaciones de producción.

2* Las criticas a la concesión de créditos -en especial censales - a labradores como medio de desposeer a éstos de sus propiedades han sido desarrolladas por varios autores. Véase, entre otros, VINAS y MEY, C., El problema de la tierra en la España de los siglos xvi y xvit. Madrid, Centro Superior Investigaciones Científicas-Instituto Jerónimo Zurita, 1941, pág. 38. SALOMON, N., La vida rural castellana en tiempos de Felipe II. Barcelona, Planeta, 1973, pág. 255; Marcos Martin, A., Economia, sociedad, pobreza en Castilla. Palencia, 1500-1814. Palencia, Diputación Provincial, 1985, vol. I, págs. 154-155; Gomez Álvarez, V., Estudio histórico de los préstamos censales en el Principado de Asturias. Oviedo, Ediciones de Bibliófilos Asturianos, 1979, pág. 34 y AtIENZA, A. Propiedad, explotación y rentas: El clero regular zaragozano en el siglo xvil. Zaragoza. Diputación General, 1988, pág.124. 